\title{
EFEKTIVITAS PROGRAM KELUARGA HARAPAN (PKH) DI DESA HAUWAI KECAMATAN HALONG KABUPATEN BALANGAN
}

\author{
Norsanti, Wiwin Safitri \\ Sekolah Tinggi Ilmu Administrasi (STIA) Amuntai \\ Email: Santisabila07@yahoo.com
}

\begin{abstract}
The Hope Family Program (PKH) is one of the programs launched by the central government to reduce poverty in Indonesia. This program is implemented by providing non-cash assistance to poor households in the form of education and health assistance. In the authors' initial observations, it was found that there was an increase in the number of PKH participants in Balangan Regency, namely in 2017 only 2,219 households and in 2018 there were 3,863 households. The increase in the number of PKH program participants raises the question whether the program that has been running so far has been effective in reducing the existing poverty problems. The results showed that the Family Hope Program (PKH) in the village of Hauwai was effective enough to help people who were very poor and vulnerable especially to access education and health. The factors that influence the effectiveness of the Family Hope Program $(P K H)$ are KPM's willingness to fulfill its obligations as well as facilities and infrastructure for Very Poor Family (KPM) coordinators and assistants.
\end{abstract}

Keywords: hope family program, planning family program

\section{PENDAHULUAN}

Masalah kemiskinan di Indonesia masih menjadi sorotan utama terkait dengan upayaupaya pemerintah untuk meningkatkan kesejahteraan masyarakat. Kemiskinan merupakan fenomena dan masalah sosial yang selalu dikaji oleh pemerintah baik pusat maupun daerah. Hal itu dikarenakan salah satu faktor penghambat kemajuan dalam pembangunan suatu bangsa adalah tingginya angka kemiskinan. Kemiskinan juga dapat menyebarkan dampak yang negatif terhadap tatanan sosial secara menyeluruh. Kemiskinan merupakan muara dari masalah sosial lainnya seperti masalah kesehatan, kriminalitas dan masalah lainnya. Kompleksnya persoalan kemiskinan membutuhkan upaya penyelesaian yang bersifat utuh dan menyentuh seluruh aspek kehidupan masyarakat serta dilaksanakan secara terpadu dan terorganisir secara baik. Banyak pendapat dan asumsi dari para pengamat yang mengatakan bahwa kemiskinan itu dipicu oleh krisis ekonomi yang berkepanjangan di negeri ini.
Pemerintah sudah meluncurkan beberapa program bantuan seperi raskin, BLT dan program-program bantuan lainnya untuk mengatasi masalah kemiskinan. Namun program-program bantuan tersebut belum sepenuhnya bisa menyelesaikan permasalahan kemiskinan di negara ini. Hal ini terlihat dari masih tingginya angka kemiskinan di Indonesia yaitu mencapai 25,95 juta orang $(9,82 \%)$ (BPS, 2019).

Adapun persoalan kemiskinan yang terdapat di Kabupaten Balangan khususnya di Kecamatan Halong, salah satunya disebabkan oleh masih rendahnya kualitas sumberdaya manusia, yang mengakibatkan rendahnya kemampuan masyarakat bersaing dalam memperoleh lapangan pekerjaan. Hal itu menjadi penyebab masih tingginya tingkat pengangguran dan kemiskinan. Rendahnya sumber daya manusia ini dilatar belakangi oleh tingkat pendidikan yang masih rendah.

Berdasarkan data pendidikan yang didapat dari kartu keluarga yang dimiliki oleh masyarakat yang ada di Kecamatan Halong terlihat bahwa jumlah penduduk yang 
berpendidikan Sekolah Dasar lebih banyak dibanding dengan penduduk yang berpendidikan SMP dan SMA sederajat. Selain itu, sebagian besar masyarakat di Kecamatan Halong lebih memilih bekerja di usia muda dan itupun hanya sebagai petani saja.

Mengatasi masalah fenomena tersebut, pemerintah telah menggulirkan Program Keluarga Harapan (PKH) yang merupakan pengembangan sistem perlindungan sosial yang dapat meringankan beban rumah tangga sangat miskin dalam mengakses pelayanan kesehatan dan Pendidikan Dasar. Program ini diharapkan akan bisa mengurangi kemiskinan yang diimplementasikan melalui Perpres Nomor 15 Tahun 2010 tentang percepatan penangulangan kemiskinan dan dipertegas lagi dengan Peraturan Menteri Sosial Republik Indonesia Nomor 1 Tahun 2018 tentang Program Keluarga Harapan.

Program Keluarga Harapan (PKH) merupakan suatu program pemerintah yang memberikan bantuan tunai kepada Keluarga Sangat Miskin (KSM) yang memenuhi syarat kepesertaan dan ditetapkan oleh Kementrian Sosial sebagai upaya perlindungan sosial. Program ini dilatar belakangi oleh adanya permasalahan utama pembangunan yaitu masih besarnya jumlah penduduk miskin serta rendahnya kualitas SDM.

Program tersebut mencakup dua bidang kegiatan yaitu pendidikan dan kesehatan yang memiliki persyaratan-persyaratan antara lain KSM yang memiliki anggota keluarga yang terdiri dari anak usia 0-15 tahun dan/atau ibu hamil/nifas dan berada pada lokasi terpilih. Tujuan utama dari PKH adalah mengurangi angka kemiskinan dan meningkatkan kualitas sumber daya manusia terutama pada kelompok masyarakat miskin.

PKH mulai diuji cobakan sejak tahun 2007, program ini memiliki keunikan dalam menetapkan siapa yang berhak menerima manfaat atau program dan sampai berapa lama penerima manfaat memperoleh bantuan. Bila hasil evaluasi menyebutkan bahwa penerima program telah memenuhi tujuan $\mathrm{PKH}$, maka KSM dikeluarkan sebagai penerima $\mathrm{PKH}$ (exit strategy). Sebaliknya, bila KSM penerima manfaat masih menerima $\mathrm{PKH}$ hanya dibatasi maksimal 6 tahun.
Namun dibalik tujuan yang telah di gaungkan oleh PKH angka kemiskinan semakin tahun semakin bertambah hal ini dapat dilihat dari data KSM yang perlu diverifikasi oleh para pendamping $\mathrm{PKH}$ kabupaten Balangan pada tahun 2018 meningkat menjadi $3.863 \mathrm{KK}$ dari yang tahun 2017 hanya 2.219 KK. Selain itu, media pembelajaran yang tidak tersedia membuat para KSM sulit untuk berpartisipasi dipertemuan kelompok dan menjalankan kewajibannya yang pada akhirnya tidak menjadikan mereka mandiri sehingga mereka terus-terusan menjadi KSM. Pernah juga ditemukan karena bantuan yang didapatkan berupa uang ada yang kehidupannya bisa dikatakan berkecukupan juga terdaftar sebagai KSM.

Berdasarkan uraian pada latar belakang di atas, maka dapat dirumuskan sebuah permasalahan dalam penenlitian ini yaitu bagaimana efektivitas Program Keluarga Harapan (PKH) di Desa Hauwai Kecamatan Halong Kabupaten Balangan, serta faktor-faktor apa yang mempengaruhi efektivitas Program Keluarga Harapan (PKH) di Desa Hauwai Kecamatan Halong Kabupaten Balangan.

\section{TINJAUAN PUSTAKA}

\section{Konsep Efektivitas}

Ensiklopedi Umum Administrasi menjelaskan bahwa efektivitas berasal dari kata kerja efektif, berarti terjadinya suatu akibat atau efek yang dikehendaki dalam suatu perbuatan. Efektivitas merupakan unsur pokok untuk mencapai tujuan atau sasaran yang telah ditentukan dalam setiap organisasi. Efektivitas disebut juga efektif, apabila tercapainya tujuan atau sasaran yang telah ditentukan sebelumnya. (Mutiarin, 2014). Handoko mendefinisikan efektivitas, sebagai kemampuan untuk memilih tujuan yang tepat atau peralatan yang tepat untuk mencapai tujuan yang telah ditentukan. Menurut Drucker, efektivitas berarti melakukan sesuatu yang benar atau sejauhmana kita mencapai tujuan. (Mutiarin, 2014).

Efektivitas mengacu pada kemampuan untuk memiliki tujuan yang tepat atau mencapai tujuan yang telah ditetapkan. Efektivitas juga 
berhubungan dengan masalah cara pencapaian tujuan atau hasil yang diperoleh, kegunaan atau manfaat dari hasil yang diperoleh, tingkat daya fungsi unsur atau komponen serta masalah tingkat kepuasan pengguna/client. (Wardiah, 2016).

Robbins juga mendefinisikan efektivitastas sebagai sebagai tingkat pencapaian organisasi atas tujuan jangka pendek (tujuan) dan jangka panjang (cara). Siagian juga memberikan pengertian tentang efektivitastas yaitu penyelesaian pekerjaan tepat pada waktu yang telah ditetapkan. Artinya apakah pelaksanaan suatu tugas dinilai baik atau tidak, terutama menjawab pertanyaan bagaimana cara melaksanakannya dan berapa biaya yang diperlukan untuk itu. (Indrawijaya, 2014).

Jika dihubungkan dengan kegiatankegiatan pemerintah (dalam pelaksanaan pembangunnan), efektivitastas yang hendak dicapai orientasinya lebih tertuju pada pengeluaran (output) bila dibandingkan dengan penggunaan masukan (input). Definisi tersebut sesuai dengan penjelasan Saxena, bahwa efektivitastas adalah suatu ukuran yang menyatakan seberapa jauh target (kualitas, kuantitas, waktu) telah dicapai. Makin besar target yang dicapai, maka semakin tinggi tingkat efektivitastas. Konsep ini orientasinya lebih tertuju pada keluaran. masalah penggunaan masukan tidak menjadi isu dalam konsep ini. Pada umumya organisasi pemerintah (yang tidak mencari laba) berorientasi kepada pencapaian efektivitastas. (Indrawijaya, 2014)

Berdasarkan pengertian tersebut, dapat dijelaskan bahwa efektivitastas seringkali berarti kuantitas atau kualitas (keluaran) dari barang dan jasa. Efektivitastas adalah ciri yang baik dalam suatu organisasi, dapat dilihat dari tingkat keberhasilan organisasi yang relatif seperti tercapainya suatu tujuan organisasi. Suatu kegiatan dapat dinilai efektif apabila output yang dihasilkan memenuhi tujuan yang diharapkan.

\section{Efektivitastas Program}

Efektivitastas program dapat didefinisikan sebagai tingkat perwujudan sasaran yang menunjukkan sejauh mana tercapainya sasaran program yang telah ditetapkan sebelumnya. Efektivitas merupakan sebuah patokan untuk membandingkan antara proses yang dilakukan dengan tujuan dan sasaran yang dicapai. Suatu program dikatakan efektif apabila usaha atau tindakan yang dilakukan sesuai dengan hasil yang diharapkan.. Muasaroh (dalam Mutiarin, 2014) efektivitas suatu program dapat dilihat dari aspek-aspek berikut:

1. Aspek tugas atau fungsi, yaitu suatu lembaga dapat dikatakan efektif jika melaksanakan tugas atau fungsinya, begitu juga suatu program akan efektif jika tugas dan fungsi para implementor (pelaksana) dapat dilaksanakan dengan baik;

2. Aspek rencana atau program, yang dimaksud rencana atau program disini adalah rencana kegiatan/program yang dibuat oleh pendamping PKH. Jika seluruh rencana dapat dilaksanakan maka rencana atau program dapat dikatakan efektif;

3. Aspek ketentuan atau peraturan, efektivitastas suatu program juga dapat dilihat dari berfungsi atau tidaknya aturan yang telah dibuat dalam rangka menjaga berlangsungnya proses kegiatannya;

4. Aspek tujuan atau kondisi ideal, suatu program dikatakan efektif dari sudut hasil jika tujuan atau kondisi ideal program tersebut dapat dicapai.

\section{Program Keluarga Harapan (PKH)}

Program Keluarga Harapan (PKH) adalah program yang digulirkan Pemerintah Indonesia sejak tahun 2007 yang juga disebut sebagai Program Bantuan Tunai Bersyarat (PBTB). Program Keluarga Harapan (PKH) dimaksudkan sebagai upaya membangun suatu sistem perlindungan sosial kepada masyarakat miskin untuk meningkatkan kesejahteraan sosial penduduk miskin sekaligus upaya memutus mata rantai kemiskinan yang ada di negara ini. PKH merupakan program bantuan dan perlindungan sosial yang termasuk dalam klaster 1 strategi penanggulangan kemiskinan di Indonesia yang berkaitan dengan pendidikan, kesehatan, dan 
pemenuhan dasar bagi lansia dan penyandang disabilitas berat. Pelaksanaan PKH juga mendukung pencapaian tujuan pembangunan millenium. Lima komponen tujuan Millenium Development Goals (MDGs) yang akan terbantu oleh PKH adalah pengurangan jumlah penduduk miskin dan kelaparaan, pendidikan dasar, kesetaraan gender, pengurangan angka kematian bayi dan balita, dan pengurangan angka kematian ibu melahirkan.

Tujuan Program Keluarga Harapan mengacu pada Permensos No. 1 tahun 2018 tentang PKH. Adapun tujuan PKH antara lain:

1. Untuk meningkatkan taraf hidup Keluarga Penerima Manfaat melalui akses layanan pendidikan, kesehatan dan kesejahteraan sosial;

2. Mengurangi beban pengeluaran dan meningkatkan pendapatan keluarga miskin dan rentan;

3. Menciptakan perubahan perilaku dan kemandirian KPM dalam mengakses layanan kesehatan, pendidikan dan kesejahteraan sosial;

4. Mengurangi angka kemiskinan dan kesenjangan;

5. Mengenalkan manfaat produk dan jasa keuangan formal pada KPM.
6. Keluarga Penerima Manfaat PKH berhak mendaatkan bantuan social $\mathrm{PKH}$, pendamping $\mathrm{PKH}$, pelayanan di fasilitas pendidikan, kesehatan dan kesejahteraan social, program bantuan komplementer di bidang kesehatan, pendidikan, subsidi energy, ekonomi, perumahan dan pemenuhan kebutuhan dasar lainnya.

Kewajiban peserta PKH agar dapat memperoleh bantuan tunai antara lain:

1. Memeriksakan kesehatan pada fasilitas pelayanan sesuai dengan protocol kesehatan bagi ibu hamil/menyusui dan anak berusia 0 sampai dengan 6 tahun;

2. Mengikuti kegiatan belajar dengan tingkat kehadiran minimal $85 \%$ dari hari belajar efektif bagi anak usia sekolah wajib belajar 12 tahun;

3. Mengikuti kegiatan di bidang kesejahteraan sosial sesuai dengan kebutuhan bagi keluarga yang memiliki komponen lanjut usia mulai dari 60 tahun dan/atau penyandang disabilitas berat.

Adapun besaran bantuan PKH untuk tiap komponen dapat dilihat pada tabel berikut:

Tabel 1. Besaran Bantuan Komponen PKH

\begin{tabular}{clr}
\hline No. & Komponen Bantuan & Indeks Bantuan (Rp.) \\
\hline 1. & Bantuan ibu hamil/menyusui & 1.200 .000 \\
2. & Bantuan anak usia dibawah 6 tahun & 1.200 .000 \\
3. & Bantuan peserta pendidikan setara SD/Sederajat & 450.000 \\
4. & Bantuan peserta pendidikan setara SMP/Sederajat & 750.000 \\
5. & Bantuan peserta pendidikan setara SMA/Sederajat & 1.000 .000 \\
6. & Bantuan penyandang disabilitas berat & 3.100 .000 \\
7. & Bantuan lanjut usia 70 tahun keatas & 1.900 .000 \\
\hline
\end{tabular}

Sumber: Keputusan Mensos RI, 2018

\section{METODE PENELITIAN}

Pendekatan penelitian yang digunakan adalah metode kualitatif. Pendekatan ini dipilih untuk menganalisa permasalahan yang berkaitan dengan efektivitastas Program Keluarga Harapan (PKH) di Desa Hauwai Kecamatan Halong Kabupaten Balangan. Mengacu pada ragam penelitian kualitatif, maka jenis penelitian yang digunakan bersifat deskriptif. Analisa data dalam penelitian ini menggunakan model Miles and Huberman (dalam Sugiyono, 2015). Datadata yang dikumpulkan dianalisis melalui beberapa tahapan yaitu data reduction, data display dan conclusion drawing/verification sehingga dapat diambil suatu kesimpulan. 


\section{HASIL DAN PEMBAHASAN}

\section{A. Efektivitas Program Keluarga Harapan (PKH) Di Desa Hauwai Kecamatan Halong Kabupaten Balangan)}

\section{Aspek Tugas Atau Fungsi}

Lembaga efektif jika melaksanakan tugas atau fungsinya, begitu juga suatu program akan efektif jika tugas dan fungsi para implementor dapat dilaksanakan dengan baik. Adapun yang menjadi pelaksana (implementor) dalam program PKH ini adalah Dinas Sosial yang menangani bantuan social $\mathrm{PKH}$, perlindungan dan Jaminan social. Dalam pelaksanaan program ini dinas sosial yang menangani bantuan sosial $\mathrm{PKH}$, perlindungan dan Jaminan Sosial. Dinas Sosial membentuk tim koordinasi dan sekretariat, untuk pendampingan terhadap KPM dipilih seorang pendamping

Hasil yang diperoleh dari analisis pada lembaga tersebut adalah bahwa pelaksanaan tugas pelaksana PKH sudah dilakukan dengan baik. Tim koordinasi menyusun program dan rencana kegiatan PKH serta melakukan pemantauan terhadap kegaiatan $\mathrm{PKH}$. Sekretariat (Administrator Pangkalan Data) melakukan pemutakhiran data KPM dengan dibantu oleh pendamping PKH, misalnya di desa Huawai pernah dilakukan pendeletan peserta PKH karena anak dari KPM berhenti sekolah sehingga bantuan akhirnya dihentikan. Dari wawancara dengan pendamping $\mathrm{PKH}$, beliau menyatakan sudah melakukan pendampingan kepada KPM (Keluarga Penerima Manfaat) dengan melaksanakan pertemuan kelompok untuk peningkatan kemampuan Keluarga Penerima Manfaat (KPM). Di desa Hauwai sendiri KPM dibagi menjadi lima kelompok. Kegiatan ini dilakukan dua kali dalam sebulan dengan memberikan materi yang berkaitan dengan pendidikan dan kesehatan. Kegiatan ini dilakukan di rumah ketua kelompok KPM, namun untuk pertemuan ini masih belum bisa maksimal dilakukan karena terkendala dengan fasilitas yang terbatas untuk memberikan materi misalnya LCD sehingga biasanya pemutaran video atau materi hanya bisa dilihat di laptop pendamping $\mathrm{PKH}$.
Selain itu, menurut pendamping $\mathrm{PKH}$ pertemuan tersebur belum bisa rutin dilakukan karena banyaknya desa yang harus beliau dampingi yaitu 10 desa padahal jarak antara satu desa dengan desa lain cukup jauh. Selain melakukan pertemuan kelompok dengan KPM, pendamping juga melakukan kunjungan terhadap KPM untuk memcek kondisi rumah dan anak dari keluarga penerima bantuan PKH. Pendamping PKH juga melakukan kunjungan ke fasilitas kesehatan dan pendidikan untuk memastikan keluarga penerima bantuan melaksanakan kewajibannya dengan memeriksakan kondisi kesehatan anggota keluarganya yang hamil dan anak tetap bersekolah.

\section{Aspek Rencana Atau Program}

Rencana atau program yang dimaksud rencana kegiatan/program yang dibuat oleh pendamping PKH. Jika keseluruhan rencana/program yang telah dibuat oleh pendamping $\mathrm{PKH}$ dapat dilaksanakan maka rencana atau program dapat dikatakan efektif.

Dalam melakukan pendampingan terhadap KPM, pendamping PKH di desa Hauwai menyatakan beliau membuat beberapa rencana program diantaranya:

a. Melakukan koordinasi dengan pihak kecamatan dan desa;

b. Kunjungan terhadap KPM setiap bulan untuk mencek kondisi rumah dan anak sekaligus untuk pemutakhiran data sehingga apabila ada perubahan bisa cepat dilaporkan;

c. Pertemuan kelompok dua kali dalam sebulan, untuk meningkatkan kemampuan KPM dengan memberikan materi tentang pendidikan dan kesehatan. Hal ini dilakukan agar KPM menyadari pentingnya pendidikan dan kesehatan bagi keluarganya.

\section{Aspek Ketentuan Atau Peraturan}

Efektivitas suatu program juga dapat dilihat berfungsi atau tidaknya aturan yang telah dibuat dalam rangka menjaga keberlangsungan proses kegiatannya. Menurut pendamping PKH pelaksanaan program PKH di desa Hauwai sudah sesuai dengan ketentuan dari kementrian 
sosial. Misalnya dalam penggunaan dana bantuan oleh KPM, menurut beliau sudah sesuai dengan aturan. Penggunaan dana oleh KPM diketahui dari laporan KPM sendiri. Untuk kebenaran laporan tersebut, pendamping masih kesulitan memastikannya karena pendamping PKH tidak bisa setiap saat memamtau kegiatan anggota KPM. Menurut pendamping PKH desa Hauwai, untuk memastikan kebenaran laporan KPM, pendamping hanya bisa mencek ke fasilitas pendidikan misalnya apakah anak dari keluarga KPM masih sekolah atau ke fasilitas kesehatan (seperti Posyandu) untuk memastikan ibu hamil dari KPM rutin memeriksakan kondisi kesehatannya.

\section{Aspek Tujuan Atau Kondisi Ideal}

Suatu program dapat dikatakan efektif dari sisi hasil, jika tujuan atau kondisi ideal program tersebut dapat dicapai. Kondisi ideal yang dimaksud pada program PKH adalah KPM bisa meningkatkan tingkat kesejahteraan keluarganya. Bila dilihat dari kondisi ideal masyarakat penerima bantuan, memang bantuan ini tidak secara otomatis mensejahterakan mereka karena kebutuhan mereka bukan hanya pendidikan dan kesehatan tapi masih banyak kebutuhan lain yang harus dipenuhi. Namun berdasarkan informasi dari beberapa informan yang merupakan penerima bantuan $\mathrm{PKH}$, mereka menyatakan merasa terbantu dengan adanya bantuan ini. Selain itu pendamping PKH, menyatakan ada sedikit peningkatan kehidupan dari KPM kalau dilihat dari aspek pendidikan dan kesehatan, misalnya anggota keluarga tetap bersekolah karena kalau ada anggota keluarganya yang berhenti sekolah maka otomatis bantuan tersebut akan dihentikan.

\section{B. Faktor Yang Mempengaruhi Efektivitas Program Keluarga Harapan (PKH)}

Efektivitas PKH ini tentunya tidak berdiri sendiri tetapi juga dipengaruhi oleh faktor-faktor lain. Hasil wawancara dengan beberapa informan dapat disimpulkan ada beberapa faktor yang mempengaruhi efektivitas PKH yaitu:

1. Kesediaan KPM untuk memenuhi kewajiban. Dalam program $\mathrm{PKH}$ peserta tidak hanya mendapatkan bantuan tapi mereka juga harus memenuhi kewajiban-kewajiban seperti: memeriksakan kesehatan anggota keluarga KPM baik ibu hamil, bayi, balita dan lansia serta penyandang disabilatas berat; menyekolahkan anak mereka hingga SLTA serta menghadiri pertemuan kelompok untuk meningkatkan pemahaman KPM tentang pentingnya pendidikan dan kesehatan. Namun sebagian KPM masih ada yang kurang berminat untuk hadir pada pertemuan kelompok karena jarak rumahnya yang jauh dengan tempat pertemuan dan adanya kesibukan lain dari KPM.

2. Sarana dan prasarana penunjang untuk koordinator dan pendamping $\mathrm{PKH}$ masih kurang memadai sehingga saat proses pelaksanaan program menjadi sedikit terkendala. Dari hasil penelitian penulis ditemukan bahwa sarana pendukung $\mathrm{PKH}$ untuk koordinator dan pendamping masih kurang memadai, khususnya yang berkaitan dengan sarana yang digunakan untuk pertemuan kelompok, misalnya kurangnya alat pengeras suara yang digunakan untuk sosialisasi, laptop untuk penginputan data, LCD dan alat peraga pendidikan. Padahal sarana tersebut sangat diperlukan oleh koordinator dan pendamping $\mathrm{PKH}$. seperti LCD sangat diperlukan untuk penyampaian materi baik untuk menampilkan slide materi dan pemutaran video sehingga anggota KPM yang hadir pada penyuluhan kelompok hanya bisa melihat slide materi dan video melalui laptop pribadi yang dibawa oleh pendamping PKH. Padahal materi yang disampaikan pada pertemuan kelompok berisi tentang pentingnya pendidikan dan kesehatan bagi masyarakat sehingga diharapkan dengan mereka mengikuti pertemuan ini akan tumbuh kesadaran untuk meningkatkan tingkat pendidikan dan kesehatan keluarganya. 


\section{KESIMPULAN}

Berdasarkan hasil analisis yang telah dijelaskan sebelumnya, maka dapat dapat disimpulkan bahwa Program Keluarga Harapan (PKH) pada desa Hauwai cukup efektif membantu masyarakat yang sangat miskin dan rentan terutama untuk mengakses pendidikan dan kesehatan. Faktor-faktor yang mempengaruhi efektivitas tersebut adalah kesediaan KPM untuk memenuhi kewajibannya seperti memeriksakan kesehatan anggota KPM, menyekolahkan anak sampai tingkat SLTA dan menghadiri pertemuan kelompok untuk meningkatkan kemampuan KPM serta sarana dan prasarana bagi koordinator dan pendamping KPM.

\section{REFERENSI}

Indrawijaya, Adam Ibrahim. 2014. Teori, Perilaku, dan Budaya Organisasi. Bandung: PT Refika Aditama.

Mutiarin, Dyah \& Arif Zainudin. 2014. Manajemen Birokrasi dan Kebijakan (Penelusuran Konsep dan Teori). Yogyakarta: Pustaka Pelajar.

Sugiyono. 2015. Memahami Penelitian Kualitatif. Bandung : CV Alfabeta.

Wardiah, Mia Lasmi. 2016. Teori Perilaku dan Budaya Organisasi. Bandung: Pustaka Setia.

https://www.bps.go.id./pressrelease/2018/07/16/ 1483/persentase-penduduk-miskin-maret2018-turun-menjadi-9-82-persen.html. Diakses Juni 2019. 